\title{
Job Crafting and Identity in Low-Grade Work: How Hospital Porters Redefine the Value of their Work and Expertise
}

\author{
Alison Fuller ${ }^{1}$ (D) $\cdot$ Lorna Unwin ${ }^{1}$ \\ Received: 16 September 2016 / Accepted: 26 December 2016 / \\ Published online: 27 January 2017 \\ (C) The Author(s) 2017. This article is published with open access at Springerlink.com
}

\begin{abstract}
Over 25 years ago, Brown and Duguid (Organisation Science, 2(1), 40-57, 1991) highlighted the differences between the way organisations formally describe and delineate jobs and the actual practices of their employees. This paper combines ideas from their seminal contribution with theories of 'job crafting' and identity to examine the agentic behaviour of employees in low-grade, 'dirty work' as they utilise their expertise and practices to (re)frame their occupational identities and challenge their prescribed job boundaries. The evidence for the paper comes from a qualitative study of hospital porters in the UK's National Health Service. It argues that this combined theoretical approach provides a potential research and employment framework to challenge the abstracted and stereotypical conceptions of the expertise related to low-grade jobs.
\end{abstract}

Keywords Care $\cdot$ Identity $\cdot$ Hospital porters $\cdot$ Job crafting $\cdot$ Agency $\cdot$ Resistance $\cdot$ Expertise $\cdot$ Low-grade work · 'dirty work'

\section{Introduction}

It is assumed that individuals who proactively engage in revising and adjusting their work tasks and activities are more likely to be in jobs characterised by high levels of discretion and expertise. Such jobs are usually associated with people with advanced educational attainment (Staw and Boettger 1990). In contrast, jobs designed around tightly prescribed tasks are regarded as providing little scope for employees to use discretion and initiative to shape their role (Fuller et al. 2007). If, in addition, the job has low status and low pay, is

Alison Fuller

alison.fuller@ucl.ac.uk

1 UCL Institute of Education, 20 Bedford Way, London WC1H OAL, UK 
located on the bottom grade of an organisation's employment structure, and requires no formal educational qualifications for entry, expectations about employee discretion and workplace learning are likely to be very modest (Lloyd et al. 2008).

Yet, many research studies of workplaces have shown that the way individuals develop and utilise their expertise is often richer than a simplistic reading of their job role, status and working conditions might suggest. Billett et al. (2004, p.238 italics as in original text) remind us that, '...there is an interdependence between what is afforded individuals by social practice, and how they elect to engage with and construct what is afforded them by the social practice'. Individuals' behaviour, decision-making and identity in the workplace is shaped and reshaped by the dynamic interplay between their biographies, values and perceptions. Hence, as Billett et al. (2004, p.237) explain, '... the quality of their engagement in these practices will not be uniform. Full-bodied participation in one social practice can be contrasted with reluctance in another' (see also Billett and Somerville 2004).

In this paper, we explore the agentic dimension of workplace participation in relation to employees in jobs often characterised as 'dirty work', that is jobs having 'physical, social or moral taint' (Hughes 1951 cited in Ashforth and Kreiner 1999 p. 415-416). Through our research with a group of hospital porters in England, we identified ways in which they developed and utilised their expertise in the workplace in order to exert their occupational values and to create positive occupational identities. The job of the hospital porter is positioned institutionally within the United Kingdom's National Health Service (NHS) as low-grade, low-paid and low-skilled, and is restricted to the manual labour logistics of moving patients, equipment and specimens within hospitals. The porters revealed, however, that they regarded listening and talking to patients as central to the NHS's commitment to not only patient safety, but to patient care more generally. Hence, they were disrupting the restrictive prescriptions of their job descriptions in response to their own occupational values as shaped by the everyday dynamic contexts in which they worked. In order to examine this, we combine insights from Brown and Duguid's (1991) theorisation of organisational learning with more recent work on the concept of 'job crafting' by Wrzesniewski and Dutton (2001) and Wrzesniewski et al. (2003) and the work of Billett et al. (2004) on the agentic nature of workplace participatory practices, identity and learning. We argue that this provides a robust framework for revealing: a) the ways in which care is integral to the hospital porters' practice and the role they play within the hospital; and b) the development of a narrative about the value of their work that runs counter to their institutional positioning and required work practice.

Following the Introduction, the article is organised in six further sections. First, we provide an overview of relevant theoretical perspectives. Second, the context of the porters' employment within the NHS is outlined, with reference to both 'good' and 'bad' aspects of their employment status. Third, we describe our methodological approach and the characteristics of the porter sample. In the fourth and fifth sections, evidence illustrating the ways in which porters contribute to patient care is presented and discussed. Conclusions are drawn in the sixth and final section. 


\section{Theoretical Perspectives and Framework}

Brown and Duguid (1991) highlighted the differences between the way organisations formally describe and delineate jobs and the actual practices of employees. They argued that basing assumptions about the way employees experience work on the formal design and characteristics of their jobs overlooks how employees participate in, shape and reshape their everyday work practices. They warned that: 'Abstractions detached from practice distort or obscure intricacies of that practice' (1991: 40 emphasis in the original). Drawing on Orr's (1990) ethnographic study of photocopier technicians, Brown and Duguid (1991, p.41) contrasted 'canonical practice' (an organisation's 'espoused practice') with 'non-canonical practices' (the actual practices that staff engage in and learn through to get the work done). Creating job specifications based on canonical practice inevitably generates an over-simplified representation that fails to recognise and understand the learning, knowledge and skills employees deploy to navigate the demands and complexities of everyday work.

Brown and Duguid's distinction between canonical and non-canonical practices has general applicability because it is not limited to high-level jobs or highly educated employees. If, via a job description, a role can be mapped and articulated in terms of a narrow set of 'simple', easy to learn procedural tasks, it follows that the qualifications for entry will be low with limited need for formal training. This in turn provides a rationale for the job to be linked to low pay and grading. Drawing on the Bourdieusian concept of 'misrecognition', Brown and Duguid highlight how abstracted representations of jobs fail to recognise the skills workers actually need and deploy in practice. This means that ' ...in the corporation's eyes practices that deviate from the canonical are, by definition, deviant practices' (ibid, p.42). Employees by exerting their agency may, therefore, themselves feel 'deviant' and, as such, may prefer these aspects of their work to remain under the organisational radar.

Although Wrzesniewski and Dutton (2001) and Wrzesniewski et al. (2003) do not cite Brown and Duguid's work, we suggest that their approaches are complementary. Their concept of 'job-crafting' coheres with the view that jobs are not reducible to the formal specification of tasks and responsibilities. It also explicitly includes the improvisational dimension of 'crafting' which employees can exercise in jobs that appear from their formal descriptions to have limited potential for their scope and boundaries to be redrawn. Wrzesniewski and Dutton (2001), p.179) define job crafting as:

... the physical and cognitive changes individuals make in the task or relational boundaries of their work. Thus, job crafting is an action, and those who undertake it are job crafters. Our perspective illuminates how, when, and why employees are likely to craft their jobs, and how crafting revises both employees' work identities and work meanings.

This suggests that all workers potentially have the agency to exercise (at least some) discretion in formulating and (re-)framing the purpose of their work, and in so doing can change the nature of their tasks, their work relations and identity. Wrzesniewski and Dutton (2001) distinguish their concept of job crafting from that of Ilgen and Hollenbeck (1992). The latter suggest that although workers may be able to alter tasks, the job itself does not change, whereas, Wrzesniewski and 
Dutton (2001, p.181) argue that 'the job (and its tasks), its meaning, and employee identity all change when job crafting occurs'.

Wrzesniewski et al. (2003) undertook research in hospitals in the United States to explore whether cleaners would or could engage in caregiving activities even though providing care was not part of their job description, hence not, in Brown and Duguid's terms, a canonical practice. They found that the cleaners were acting as 'caregivers' by providing direct care to patients as well as indirectly caring for doctors, nurses and visitors, hence their workplace interactions were characterised by what the researchers termed 'caring moves'. Drawing on Noddings (1984), Wrzesniewski et al. (2003, p.12) defined 'caring moves' as 'behaviors undertaken on another's behalf in service of their well-being.' They identified three types of 'caring moves': a) 'responding to requests'; b) 'conversation-making'; and c) 'entertaining' (Wrzesniewski et al. 2003, p. 45). In the first two, the cleaners were going beyond the standard routine of their prescribed daily job tasks by listening to patients' needs, responding to their individual cleanliness requirements and engaging them in conversation. In the case of 'entertaining', some cleaners used music and laughter to raise patients' spirits. They exerted agency to ensure they could infuse their work practices with their occupational and personal values. Similarly, Hennessy and Sawchuk (2003) found that case officers in Ontario handling welfare and disability benefits claims had developed collective strategies ('work-arounds') to maintain the level of service they believed their clients deserved. This aspect of agentic agency forms a key part of Billett et al. (2004) study of the workplace participatory practices of three people in the contrasting roles of trade union official, grief counsellor and IT consultant. In their theorisation, Billett et al. (2004, p.239) drew on Valsiner's (1994) concept of the 'relatedness' between the values of individuals and the 'mores of the social practice' in their occupational and organizational contexts: 'Individuals' agentic actions are directed to sustaining and extending their practice in ways that are not always consistent with the goals of the workplace'.

Wrzesniewski et al. (2003) identified four sources of knowledge used by the clearners in their decisions about whether to provide care and the most appropriate kind of 'caring move' for each specific context, and, crucially, which practice would avoid or not risk harm to the patient:

1. Knowledge from observation (e.g. notes on boards in the nurses' work stations, and signs on patients' doors about how to approach them)

2. Knowledge from relationships (e.g. with nurses, doctors and administrators)

3. Knowledge from perspective-taking (i.e. taking the perspective of the individual they were dealing with and adjusting their behaviour and actions accordingly)

4. Knowledge from personal experience (of illness and working in hospitals)

This range and depth of the cleaners' knowledge reflects findings from Livingstone and Sawchuk's (2003) ethnographic studies of what they termed the 'hidden knowledge' of Canadian workers. Wrzesniewski et al. (2003) showed how the cleaners could influence and alter the social and interpersonal relations and tasks that imbued the experience of work even in routine and apparently limiting or 'dirty work' contexts (Berg et al. 2003). 


\section{Implications for Occupational Identity}

In line with insights from symbolic interactionism, it has been argued that people's sense of identity (in which occupational identity plays a part) is partly developed in response to how they are viewed by others including colleagues (e.g. Billett 2011; Felstead et al. 2009a, b; Collin et al. 2008). Hence, those in occupations accorded high social status have the opportunity to benefit (in identity terms) from the security and esteem accruing by virtue of their job. The way jobs are constructed, characterised and positioned within organisations provides a framework within which workers receive messages about how they are seen (Gabriel 1999). It follows that it will be harder for workers in low-grade jobs to develop and maintain positive self-esteem and sense of occupational identity than for their peers in high status, socially well-regarded occupations. However, Ashforth and Kreiner (1999), p.416) explain that, where the occupation lacks social validation, there is an incentive for those working in the occupation to construct a counter 'esteem enhancing' identity to protect themselves against the negative perceptions of others.

Wrzesniewski et al.'s (2003) account illustrates how despite, or perhaps in resistance to the formal and social representation of the job, hospital cleaners emerged as 'job crafters'. Through constructing their role as primarily relational, interactive and interpersonal, the cleaners participated in non-canonical practices that diverged from those espoused in the job description. Engaging in caring practices in the course of their daily work enabled the cleaners to develop an 'esteem enhancing' identity by crafting their jobs as care work.

Before turning to the hospital porters' evidence, we outline aspects of the background to hospital portering in the UK, discuss the nature of porters' employment status and describe the way their work is organised.

\section{The Porters' Employment and Work Context}

Our research took place in a large hospital in England under the management of an NHS University Hospital Trust (hereafter referred to as 'the Trust'). The NHS (one of the world's largest employers with around 1.4 million employees) is a multi-layered and highly complex productive system (Felstead et al. 2009a, b). The State controls national policy, regulation and funding and the frontline units (e.g. hospital wards and clinics, and doctors' and dentists' surgeries) deal directly with patients. NHS Trusts are located at the meso level of the system and, although they are constrained by macro level governance and funding, they still have considerable levels of autonomy, as do the units at the micro level.

In recent years, the NHS has been subject to a number of highly critical and well-publicised reports about the nursing and wider medical failures in some hospitals to meet the national standards set for patient are and safety. The most notorious case involved the Mid Staffordshire NHS Trust in England during 2005 to 2008. The public inquiry established to investigate the problems concluded in its report to the House of Commons that: 'Listening to patients and the public and responding to what they say is at the heart of a compassionate healthcare system. Patients must be involved and given their say at 
every level of the system.' (House of Commons 2013: 13). In its response the Department of Health stated that 'By bringing all this together, all who work to provide patient care, from porters and cleaners to the Secretary of State, will be working effectively in partnership in a common and positive culture.' (Department of Health 2014: 66). This was the only reference to hospital porters in either document yet, as this paper will show, porters regard listening and responding to patients as a key manifestation of the occupational values that underpin their practice.

Indicators of pay, grade and status suggest some grounds for seeing hospital porters' employment through the lens of the 'bad' or 'lousy' job thesis (Goos and Manning 2003, Lloyd et al. 2008, Kalleberg 2013). Portering, like hospital cleaning, can be viewed as 'dirty work' as porters have a 'servile relationship' with others in the workplace (social taint), an indicator of low occupational status. In addition, their work includes handling and transporting specimens and disposing of waste (physical taint). Whilst the concept of 'dirty work' is linked to how jobs are perceived of their social status, debates about the nature of good and bad jobs are linked to notions of standard and non-standard employment, with the former associated with regulated employment relations, and covered by collective bargaining arrangements (Kalleberg et al. 2000). In research on low-wage workers in the NHS, Grimshaw and Carroll (2008, p.168-9) argue that 'co-ordinating institutions' such as 'harmonised and coordinated national pay structures' mitigate the bad job characteristics (primarily low pay) associated with some groups of low-paid NHS support workers such as porters, cleaners and healthcare assistants.

The porters in our study were permanent members of staff, whose terms and conditions comply with NHS arrangements for entitlements to holiday and sick pay, pension, and parental leave. The job role does not require applicants to have any formal qualifications and porters are on the lowest (Band 1) of the NHS's nine Pay Bands. The Trust is subject to nationally defined career structures, and education, training and career pathways under the NHS career framework. Efforts to enhance the training and career opportunities available to support workers have been highlighted in NHS policy initiatives; for example, the notion of a 'skills escalator' has been developed as a mechanism for facilitating mobility and progression (Department of Health 2001). The number of support workers (those supporting the work of nurses and doctors, but not including nursing assistants or clerical staff) in the NHS including porters, declined steeply (by 27\%) between 1995 and 2005, the only group of employed staff to record a reduction (Grimshaw and Carroll 2008).

Like hospital cleaning, the portering function is susceptible to being outsourced, or to agency staff being used rather than increasing the pool of permanent workers. The job is vulnerable, therefore, to workforce strategies designed to achieve numerical flexibility, as well as having some other 'bad job' characteristics associated with low pay in absolute (just above the UK's minimum wage) and relative terms (given the porters' position at the bottom of the pay and grade band hierarchy). Nonetheless, as outlined above, they have access to some benefits associated with regulated, standard employment conditions, indicating that a straightforward 'lousy job' categorisation is not entirely appropriate. 
The NHS website states that porters provide an important function within the hospital, but caregiving is not specified as an integral or explicit part of the job. The website lists the porter's duties as moving:

- patients on trolleys or in wheelchairs

- stores and equipment

- samples of patients' blood

- linens

- post and parcels

- waste

- cylinders of gas

- trolleys of food and drink

In addition, it states that porters may have other duties including:

- cleaning and tidying outside areas and gritting in cold weather

- cleaning indoors

- replacing curtains round beds in wards.

\section{The Organisation of Portering in the Trust}

Portering sits within the Trust's non-clinical services division and is overseen by the Operations Centre, which can intervene in the porters' work to solve logistical issues through telephone consultations with the porter supervisors or manager about prioritising particular tasks. Porters cover all areas of the hospital via a seven-day a week, 24-h shift system. Each day some porters are allocated to Theatre, Radiology and Emergency where they are given tasks by staff within those departments. The rest of the porters work in the 'pool' or relief teams. Requests for porters from across the hospital and are logged and timed through a computer system by the supervisors. Portering has three tiers of management: supervisors; two Head Porters; and the Portering Manager, with further administrative support provided by the Pest Control Officer. Hence, in terms of the hospital's organisational structure, portering is clearly located as a non-clinical function with accountability to non-clinical service managers. This confirms that in positional and relational terms, the porters are not conceived as part of the care-giving part of the workforce.

\section{Methodology}

The Trust funded our research as a way to explore ways to improve the development and career progression of its porter workforce and the potential of the hospital workplace as a learning environment. Evidence was gathered by a variety of qualitative methods, including face-to-face individual interviews with 20 porters (equating to one fifth of the total permanent porter population). Individual interviews were also conducted with 10 employees at managerial and supervisory levels, including the manager of the portering department. Participation in the study was voluntary and we adhered to the ethical codes 
of the British Educational Research Association's Code of Ethics and the NHS. All names have been anonymised in this paper to protect participant confidentiality. The interviews, which lasted between 60 to $90 \mathrm{~min}$, were recorded and transcribed. They explored a range of themes relating to the porters' workplace learning environments, such as the organisation of porters' work, provision for training, inter- and intra-departmental communications and relationships, formal and informal learning experiences, and the porters' views on the potential introduction of National Vocational Qualifications (NVQs) for portering. They also explored the porters' experiences of education and training prior to becoming a porter.

The data were initially analysed using the 'expansive - restrictive framework', which enables the micro context of workers' participation in and learning through the practices of workplace communities to be integrated into a broader conception of the productive system with which the environment is located (Fuller and Unwin 2004, 2010; Felstead et al. 2009a, b). This contextual dimension was essential to our understanding of how and why the porters were reinterpreting the boundaries of their job description. An initial reading of the transcripts showed clearly that many of the porters described examples of how they deviated from their job descriptions. Using a deductive approach, we checked their accounts against the job descriptions and then used a thematic approach, informed by Wrzesniewski et al.'s (2003) concept of job crafting and Billett et al.'s (2004) work on identity to code the transcripts to highlight the divergence. This latter stage of the data analysis has informed the argument in this paper.

\section{Sample Characteristics}

The porters had varied occupational and educational backgrounds and had all previously worked in other jobs, including, for example, as factory workers, builders, postal workers and sailors (including one merchant ship captain). Some had worked in offices and one was a former beautician. The longest serving participant had been a porter for 34 years, whilst the shortest period was just two months. The majority of interviewees had worked as porters for over five years and were therefore experienced in their roles. Ages ranged from 26 through to $65(20-30: n=3 ; 31-40: n=4 ; 41-50: n=5 ; 51-60: n=5$; 61-65: $n=3$ ).

Interviews were undertaken with 18 males and 2 females reflecting the gender balance in the total porter population. The porters' prior educational attainment varied from those having no qualifications $(n=4)$ to one who had a Master's degree, whilst some had school leaving certificates and work-based qualifications. The porters were told at their hospital induction that speaking to patients (other than to respond to direct enquiries) was not part of their role.

\section{Porters as Healthcare Workers?}

The data revealed that the porters were very aware of the divergence between the canonical representation of their job functions and the way they themselves conceive 
patient care as being at the heart of their role. In his interview, Kevin captured this awareness with an ironic comment about how much happens beneath the managerial radar:

...we're there basically just to push the bed, transfer the patient, but there's a lot of things we do which we're not supposed to just to make the job easier. (Kevin, hospital porter)

It is this aspect of the study's findings and how it might be explained that is the focus of the following discussion. First, we draw on Wrzesniewski et al.'s (2003) research to illustrate how the three kinds of 'caring moves' ('responding to requests,' 'making conversation,' and 'entertainment') practised by hospital cleaners can also be identified as a feature of the porters' interactions with clinicians, patients and other colleagues. We then identify a fourth kind, which we have termed, 'practising care'.

\section{Care Moves}

The interview data revealed many examples of the porters 'responding to requests' as this forms an integral aspect of the labour process. In the following example, Malcolm explains the need to respond quickly to requests from clinicians in the Emergency Department for blood supplies:

When a person comes in through Accident and Emergency, and they've used up all the emergency blood in the fridges, we got to run to Path lab, get all the spare blood they can handle at the time $[\ldots]$ and if that runs out, porters got to go over to main Transfusion - it happens more on night shift, when there's just a skeleton crew, really - you can be running all night long for one patient. People don't realise... just how much we do do to save lives.

Whilst being responsive to requests plays an essential role in the work of the hospital and is important to patient well-being, it is the way the porters approach tasks and the manner of their practice which strongly illustrates their concept of caregiving. The porters acknowledged that they were not supposed to ask patients direct questions about their illness or condition, but they provided numerous examples of how they 'make conversation' using their initiative, judgement and discretion to decide when and how to interact with patients. Jack explained: 'I don't know, use your instinct, you know; you look at the patient and (you think) is the patient in a good mood to talk to you?'. In another example, Raymond discusses the importance of understanding the patient's point of view, or in Wrzesniewski et al.'s (2003) terms illustrating 'knowledge from perspective-taking':

You've just got to go there [the ward], be approachable, be friendly, not over the top, you know, you can't be in there joking around when people are sick and they're not feeling like it, you've got to meet them on their level all the time, and 
execute the job in the appropriate manner, not speeding, you know, appreciate the person's laid down and you're not spinning round corners.

Lee identified how working with more experienced porters has helped him learn how and when to talk to patients ('knowledge from relationships'):

Some of them [porters] have 30, 35 years and that, and how they talk to patients and...which I find is great, even though you can have a real bad day, at the end of the day you've still got to have a cool head; you're here to support the patient who's being transferred, whatever, and if they want to start a conversation, 'What's the weather like outside?', talk nice back to them. I've found working with the more experienced ones, it's been a pleasure, because you pick up their mentality and their attitude towards staff as well as patients.

The following quotations illustrate how porters 'entertain' patients as part of their repertoire of caring moves, with the effect of creating a more cheerful and relaxed atmosphere:

I usually go in and say "okay, who wants a free op today then?" They all say "not me, not me!... most of them [patients] you have a laugh and a joke they've forgot about what they're going down the theatre for and they'll say "thank you very much". (Denzil)

...And the partner I work with, we make a habit of, if you see someone a bit nervous, make a joke about something, by the time they get down there they're laughing. And it just takes their mind off what's happening. (Tony)

The data showed that, in addition to caring moves, the porters offer a fourth more direct kind of involvement in healthcare. We have termed this, 'practising care', as it represents the porters' practice of drawing on their knowledge and experience to take action, initiate dialogue or use their judgement in support of clinical interventions or to avoid patient harm. Malcolm, who had worked as a porter in the same hospital for over 30 years, explained how porters assist, support and even 'teach' student nurses how to use the syringe pump drivers effectively, with clear implications for improving the quality of care received by patients:

Even a first year student nurse, they'll not always know what you're doing with the patient; it's not their fault, they're just learning. But we generally advise them what to do and syringe pump drivers, that it can't actually lay on the beds, got to be on the drip holder, little bits like that.

Interviewer:Sometimes you're essentially coaching an inexperienced medic?

Yeah. A lot of the time we do that; they ask us for advice or we... if we don't like something that's going on, when we're out in the corridor we will 
sort of physically move it ... or just mention it to them, "well, actually, that shouldn't be going like that." Like syringe pump drivers we all, a lot of us take them mainly with us to appointments... but a lot of the medical staff or nurses or quite a few of the porters don't take the mains lead and on certain drugs, it's got to be kept going you know all the time, it can't be stopped; something to do with if it's stopped a few minutes, it's quickly goes out of the blood system; that sort of stuff, and you think of, but a lot people don't, they just unplug it, take the mains lead out, and you're off.

Similarly, Lee outlined how he is able to use his clinical knowledge and experience to make decisions about which task to prioritise:

...if I turn around and say I want a bag of ice for Intensive Care and...platelets, you prioritise the platelets, they'll be first, because that's to stop the bleeding; ice is just to cool someone who's too hot, cool 'em down, but platelets and bloods, they prioritise those.

In the following example, Malcolm, describes how he uses his interpersonal skills to make conversation that will support nurses in their task of taking patients to the mortuary:

I always give the nurse a chance to say goodbye to the patient before I open the fridge door, bring the fridge tray out, put the child or whatever onto these sliding drawers and put them back in and shut the door. A lot of the nurses don't like seeing that bit happen. So I always give a lot of them the choice, "would you like to stay and watch me put the deceased in the fridge?" Or "if you wish you could just wait outside the door and I'll do that bit."

Malcolm also described how, given his long experience, he could contribute to a potentially life-saving procedure:

...we've got the benefit of looking and listening so if we're by ourselves, cut off from somewhere with someone, you know roughly what to do. Like a tracheoscopy; I've seen it done several times on the wards. What I've learnt since in dire emergency, as a last resort, if I was on the phone to someone, to a medical team, and they said sort of look, you need to do this, that and the other, at least I've got some sort of knowledge of what they're on about and I'd just go by them, really. But I would never attempt it by myself, obviously. But at least I'd know what they're on about.

In the following section, we present evidence showing that the porters are contributing to patient care within a context in which they feel devalued, and highlight the 'interpersonal and institutional cues' (Wrzesniewski et al. 2003) that enable them to develop an esteem enhancing occupational identity. 


\section{Job Crafting and Identity in a Constrained Environment}

It's not as bad as when I first started, but say NHS hierarchy, you start off with your surgeons at the top and the porters are at the bottom. But I know if the porters weren't there, I know personally that a lot of the jobs wouldn't get done. (Kevin)

The positioning of portering at the bottom of the occupational hierarchy together with the formal representation of the role as moving patients and materials from A to B, means that the porters' practice is likely to be judged in narrow logistical terms. This is despite the fact that their ability to meet performance targets is affected by the behaviour and actions of other, mainly clinical, staff. The evidence suggests that porters craft their work as care despite it not being included as a mandated part of their job description and at the same time as feeling devalued by the institution and at times by other staff.

Wrzesniewski et al. (2003) emphasise the importance of interpersonal and institutional cues in providing the relational resources for employees to develop a collective occupational identity. As discussed earlier, where an occupation is one which lacks societal validation, there is an incentive for those working in the occupation themselves to construct a counter 'esteem enhancing' identity to protect and defend themselves against the negative perceptions of others (Ashforth and Kreiner 1999). Our findings showed that many of the hospital porters were utilising and responding to negative interpersonal and institutional cues to resist an occupational identity characterised by their low-grade 'dirty work' status, and to create a much more positive identity built around their commitment to caring for patients. In some instances, the porters' construction of a counter 'esteem enhancing' identity was at least in part being accomplished through their distancing from messages (e.g. 'it's not your job to...') about the limits of what should and should not be part of their role.

Most porters usurp the regulations (institutional cues) governing their jobs, and thus the canonical practice, by responding to the pressures that arise during the course of everyday work:

We're not supposed to go on the trolley for notes 'cause that's patients' confidentiality but you ask, you ask a nurse, you ask the ward clerk, they're busy so we've got to go in there and just get the notes or say to the nurse, er, like two or three litres on the oxy(gen)... yeah, that's OK but we're not supposed to do it but if there's a nurse present we'll do it. (Kevin)

The following comments illustrate how the porters' contribution to the smooth running of the hospital and the patient experience is under-estimated and undervalued, particularly by clinical staff:.

I just feel sometimes that they [some hospital staff] just look down at you. (Dennis) 
But when they turn round and say to us "You're only a porter" that really hurts..." I went to get a patient ... for a body scan ... and somebody said to me "Oh can you ask Doctor so and so" can't remember his name now, to say that so and so won't be coming. And he was down there when I got back, and I said "Oh excuse me Doctor" "I'm not talking to you!" he said "I'm not communicating with you". Right? And the woman on the desk there ("cause we get on well) she looked at me, I said "well fair enough if you don't want to talk to me, I ain't going to give you the message". He said "Well I'm still not talking to you, you are nothing". This was a doctor!' (Jim)

The interviews revealed how managers were perceived to be quick to reprimand, but slow to praise. Porters who received thanks from other staff or wards within the hospital when they had performed their work to a higher than expected standard were proud of their achievements, as Barnaby explains:

We got a letter of praise... A member of staff saw me and sent a letter down to my boss, and he got it, you know. I do the job the best I can; I'm working with human beings. They could be my mum, my dad, my brother, my sister.

Despite the general lack of positive feedback, the porters said they continued to work as best they could and were willing to go out of their way to ensure the patients' needs were served, at times 'practising care' to correct the actions of nursing staff:

But so many times you've gone onto a ward, you've had to move a patient across, and the nurses just haven't got a clue what they're doing... And if I didn't step in on a couple of times and said "Oi, you're going to do some damage here, you've got to take care"... Well, you have to [step in]. If you've got a patient that's probably ill and the nurse says, "Well, you don't need an escort", you can turn around and say "No, sorry, you're going to need an escort, because this patient is just a bit too dodgy, to take this patient without an escort." (Harry)

The porters provided numerous examples of how patient well-being remained their priority even when they were being devalued by other staff:

Some of them just treat you as saying I'm your shoe! You are only a porter to them, some of them, you know. Yeah. Some of them do get nasty. Well you've just got to just carry on, you know what I mean? Because you've got to think of that patient, you know, that's the thing. The patient is the main person. (Thomas)

You've just got to go with the flow, basically. Just go with the flow. Because at the end of the day, you're in this job because you enjoy it, but at the end of the day the most important thing is the patient's wellbeing isn't it? (Jim)

However, not all the porters resisted negative cues, arguing that, given the pay and status of the job, it would not be rational to go beyond the job description. This can be seen as agentic in that individuals were constructing themselves as knowingly 
performing the job in line with institutional expectations whilst at the same time creating distance between the ascribed role and themselves. As such, they indicated that their individual identity was not for appropriation by the employer or institution by, for example, seducing them into providing what might be perceived as unrewarded emotional labour, or into taking risks with their own safety. Dennis commented:

If there was a patient kicking off on one of the wards ... security would have to do the job, they couldn't expect me to do it, 'cause I'm quite sure the security people are on a lot more money than what I am.

Whereas all the porters were drawing on the relational resources available in the workplace, including intragroup relations, not all of them emerged as job crafters. For example, Denzil sought to differentiate his non-canonical practice and commitment to the role from what he perceives to be the minimalist approach (canonical practice) adopted by some of his peers:

I think some porters come in and think I'm just gonna do portering and that's it, well that's up to them. You know, it's just one of them jobs. I mean some people just do it just to get a job... Which is up to them...I suppose you gotta think they want money and that's it. (Denzil)

Here again, we see evidence of the way individuals' biographies, values and dispositions shape their decisions about how they will engage (at any one time) in work practices, both as individuals and relationally with colleagues. Billett et al. (2004, p.237) remind us that: ' ...the quality of their engagement in these practices will not be uniform. Full-bodied participation in one social practice can be contrasted with reluctance in another'.

\section{Discussion and Conclusions}

Our research evidence revealed how hospital porters had become knowledgeable practitioners able to mobilise diverse forms of expertise in the service of crafting their job as patient care. In order to explain why many porters were engaged in significant and diverse forms of care work, despite the absence of this activity from their job description, we have drawn on three complementary perspectives from organisational studies and have combined these with insights from Billett et al.'s (2004) work on occupational identity and social theories of learning more generally (Lave 1993). Firstly, Brown and Duguid's distinction between canonical and non-canonical practices illuminated the disconnection we found between the espoused organisational practice enshrined in the hospital's and NHS's abstracted view of the job and the attitudes, expertise and practices many porters perceived were most important in actually undertaking their role.

Secondly, Wrzesniewski et al.'s theory of job crafting enabled us to understand how and in what circumstances employees, even in low-grade positions, emerge as job crafters able to change the meaning, boundaries and relations of their work to include caring as an integral 
aspect of their practice and occupational identity. Of particular interest has been the way in which many porters, in similarity to Wrzesniewski et al.'s hospital cleaners, conceive their primary function and job-satisfaction in terms of 'caring'. This aligns with Billett et al.'s (2004) discussion of the fracture that can occur between the personal values that underpin the way individuals wish to approach their work and the expectations and norms they encounter in the workplace. When combined with theories of identity formation, the 'job crafting' thesis helps illuminate the reflexive nature of the relationship between employees and their jobs as well as pointing to the potential for individual and organisational change that arises as an effect of this relationship.

Thirdly, Ashforth and Kreiner's observation that 'people performing dirty work tend to retain relatively high occupational esteem and pride' (1999: 413) resonated with our own and others' findings. For example, Bolton's (2005) research on gynaecology has shown how female nurses forged an esteem enhancing identity out of their performance of 'dirty work' (described as such because of the social and physical taint associated with conditions such as sexually transmitted diseases). These nurses linked their gender to the satisfaction they took in performing specialist caring work with and for women. Whilst the (predominantly male) porters also highlighted their caring attitude and its centrality to their job satisfaction, they did not have access to a gendered narrative to explain this. There is a need for further research to explore the similarities and differences between male and female understandings of frontline caring work and their relationship with occupational and personal identity formation.

Our findings strongly support Brown and Duguid's (1991), p.42 argument that employers' misrecognise the actual skills and knowledge workers develop and deploy day to day. In our evidence, those porters who emerged as job crafters recognised that providing care and seeing themselves as part of the healthcare workforce ran counter to their mandated organisational role ('deviant' practise), and ascribed occupational identity. Given this, they used the cloak of their relative organisational invisibility to undertake non-canonical practices and keep their deviance beneath the management radar. It follows that those choosing not to deviate by aligning themselves with the formal concept of the job were taking a less risky option. We suggest that this points to a potential trade-off for porters between, on the one hand having access to an esteem enhancing identity associated with crafting the job as healthcare, and on the other eschewing a more positive identity in favour of the security of job compliance, in a context where there was no material gain for doing anything else.

Overall, we would argue that the porters make the hospital a better environment for patients and other staff. Hospital managers and some clinicians at the organisational level, and the NHS at a macro level may not 'see' this, but the porters' contribution is still 'real'. It is important to question the way low paid, low status work is positioned in some of the labour process and workplace learning literature as it can have the effect of closing off discussion about the contribution individuals in these kinds of jobs make to the organisations in which they work. We suggest that the framework outlined in this article could have wider applicability for analysing the divergence between espoused and actual practices and ascribed occupational identity and the identity and meanings many employees develop for themselves. From a public policy perspective in the UK and given the financial and organisational challenges facing the NHS, the continued neglect of the contribution that employees are making at the lower end of the employment hierarchy is extremely wasteful. 
In our report to the Trust, we recommended that they urgently review the current highly restricted formulation of the portering function with a view to collecting further evidence about its contribution to the hospital's efficiency and patient well-being. To assist this process, we also recommended the creation of an 'Advanced Practitioner' (AP) band within portering to recognise and differentiate higher levels of expertise and experience, and the ability to teach and mentor colleagues, particularly in relation to interpersonal skills. The AP role would indicate that some porters have expertise above the level associated with general competence and, crucially, that porters, like other employees in the NHS, are practitioners belonging to a community of practice. These steps would then enable the Trust to better integrate portering with its initiatives to enhance cross-boundary and team working across the hospital.

In their review of developments in the field of organisation studies and, in particular, the sub-field of 'institutional work', Lawrence et al. (2013): 1029-1030) raised the challenge that: 'Our practices of knowledge production, dissemination and consumption; our choices of research questions, cases and methods (e.g. where are the janitors and mechanics?) - all carry moral implications'. Our research offers a response to this challenge. It shows that the task of transforming institutions cannot and does not only lie in the hands of those actors who are positioned in the 'professional' and managerial bands of the occupational hierarchy. Through their contribution to the well-being of patients and in the ways they develop and share their institutional and occupational knowledge, the porters are making a constructive contribution by disrupting the overly restricted nature of the workplace structures and cultures.

As our research indicates, the porters' commitment to patient care, the way they cross and resist institutional boundaries and the way they disrupt the limitations of their daily routines means they are able to forge an 'esteem enhancing' identity. Thus their constructive resistance provides a more nuanced picture of working life at the 'dirty' end of the labour market. This resonates with Thomas and Davies's (2005) study of how managers in different areas of the UK's public services were responding to the impact of the discourse of New Public Management. They (ibid, p.700) argue that it is through studying what they term the 'micro politics of resistance' that we can expose the 'creative or generative dimensions of resistance'.

We are not, of course, arguing that having an 'esteem enhancing' identity is sufficient or that all employees are concerned with or engaged in constructing one. As Craft Morgan et al. (2013) argue, whilst the 'intrinsic rewards' (job satisfaction) for working with patients can be strong, the 'extrinsic rewards' for many employees involved in healthcare support activities are limited. Porters remain at the bottom of the NHS occupational grade and pay structure and their jobs are vulnerable to outsourcing trends. By shifting towards the view that all staff are knowledgeable and have expertise of value to the institution, the NHS could make a step change in the management and development of its workforce.

Acknowledgements The authors wish to acknowledge the contribution of Ian Laurie who carried out some of the fieldwork reported in this paper. We would like to thank the three anonymous reviewers who provided helpful and constructive comments on an earlier version of this paper.

Open Access This article is distributed under the terms of the Creative Commons Attribution 4.0 International License (http://creativecommons.org/licenses/by/4.0/), which permits unrestricted use, distribution, and reproduction in any medium, provided you give appropriate credit to the original author(s) and the source, provide a link to the Creative Commons license, and indicate if changes were made. 


\section{References}

Ashforth, B. E., \& Kreiner, G. (1999). "how can you do it?": dirty work and the challenge of constructing a positive identity. The Academy of Management Review, 24(3), 413-434.

Berg, J. M., Wrzesniewski, A., \& Dutton, J. E. (2003). Perceiving and responding to challenges in job crafting at different ranks: when proactivity requires adaptivity. Journal of Organisational Behaviour, 31, 158-186.

Billett, S. (2011). Subjectivity, self and personal Agency in Learning through and for work. In M. Malloch, L. Cairns, K. Evans, \& B. N. O’Connor (Eds.), The SAGE handbook of workplace learning (pp. 60-72). London: SAGE.

Billett, S., \& Somerville, M. (2004). Transformations at work: identity and learning. Studies in Continuing Education., 26(2), 309-326.

Billett, S., Barker, M., \& Hernon-Tinning, B. (2004). Participatory practices at work. Pedagogy, Culture \& Society, 12(2), 233-258.

Bolton, S. (2005). Women's work, dirty work: the gynaecology nurse as 'other'. Gender, Work and Organization, 12(2), 169-186.

Brown, J. S., \& Duguid, P. (1991). Organisational learning and communities of practice: towards a unified view of working, learning and innovation. Organisation Science, 2(1), 40-57.

Collin, K., Paloniemi, S., Virtanen, A., \& Eteläpelto, A. (2008). Constraints and challenges on learning and construction of identities at work. Vocations and Learning, 1(3), 191-210.

Craft Morgan, J., Dill, J., \& Kalleberg, A. L. (2013). The quality of healthcare jobs: can intrinsic rewards compensate for low extrinsic rewards? Work, Employment and Society, 27(5), 802-822.

Department of Health. (2001). Working together-learning together: a framework for lifelong learning for the NHS. London: Department of Health.

Department of Health. (2014). Hard truths. The journey to putting patients first, volume one, the government response to the mid Staffordshire NHS foundation trust public inquiry. London: The Stationery Office.

Felstead, A., Fuller, A., Jewson, N., \& Unwin, L. (2009a). Improving working for learning. London: Routledge.

Felstead, A., Fuller, A., Jewson, N., Unwin, L., Bishop, D., \& Kakavelakis, K. (2009b). Mind the gap: personal and collective identities at work. Studies in the Education of Adults, 41(1), 6-20.

Fuller, A., \& Unwin, L. (2004). Expansive learning environments: integrating organizational and personal development. In H. Rainbird, A. Fuller, \& A. Munro (Eds.), Workplace learning in context. London: Routledge.

Fuller, A., \& Unwin, L. (2010) 'Knowledge workers' as the new apprentices: the influence of organisational autonomy, goals and values on the nurturing of expertise. Vocations and Learning, 3(3) 203-222.

Fuller, A., Unwin, L., Felstead, A., Jewson, N., \& Kakavelakis, K. (2007). Creating and using knowledge: an analysis of the differentiated nature of workplace learning environments. British Educational Research Journal, 33(5), 743-759.

Gabriel, Y. (1999). 'beyond happy families': a critical re-evaluation of the control-resistance-identity triangle. Human Relations, 52(2), 179-203.

Goos, M. \& Manning, A. (2003). Lousy and Lovely Jobs: the rising polarization of work in Britain. CEP Discussion Papers. London: Centre for Economic Performance, London School of Economics.

Grimshaw, D., \& Carroll, M. (2008). Improving the position of low-wage workers through new coordinating institutions: the case of public hospitals. In C. Lloyd, G. Mason, \& K. Mayhew (Eds.), Low wage work in the United Kingdom (pp. 168-210). New York: Russell Sage Foundation.

Hennessy, T., \& Sawchuk, P. (2003). Worker responses to technological change in the Canadian public sector: issues of learning and the labour process. Journal of Workplace Learning, 15(7/8), 319-325.

House of Commons. (2013). The mid Staffordshire NHS foundation trust public inquiry. London: The Stationery Office.

Hughes, E. C. (1951). Work and the self. In J. H. Rohrer \& M. Sherif (Eds.), Social psychology at the crossroads (pp. 313-323). New York: Harper \& Brothers.

Ilgen, D. R., \& Hollenbeck, J. R. (1992). The structure of work: job design and roles. In M. Dunnette \& L. Hough (Eds.), Handbook of industrial/organizational psychology. Palo Alto: Consulting Psychologists Press.

Kalleberg, A. L. (2013). Good jobs, bad jobs: the rise of polarized and precarious employment Systems in the United States 1970s to 2000s. New York: Russell Sage Foundation. 
Kalleberg, A. L., Reskin, B. F., \& Hudson, K. (2000). Bad jobs in America: standard and nonstandard employment relations and job quality in the United States. American Sociological Review, 65(2), 256-278.

Lave, J. (1993). The practice of learning. In S. Chaiklin \& J. Lave (Eds.), Understanding practice: perspectives on activity and context (pp. 3-32). Cambridge: Cambridge University Press.

Lawrence, T. B., Leca, B., \& Zilber, T. B. (2013). Institutional work: current research, new directions and overlooked issues. Organization Studies, 34(8), 1023-1033.

Livingstone, D., \& Sawchuk, P. (2003). Hidden Knowledge. Toronto: Garamond Press.

Lloyd, C., Mason, G., \& Mayhew, K. (Eds.). (2008). Low wage work in the United Kingdom. New York: Russell Sage Foundation.

Noddings, N. (1984). Caring: a feminine approach to ethics and moral education. Berkeley: University of California Press.

Orr, J. (1990). Sharing knowledge, celebrating identity: war stories and community memory in a service culture. In D. S. Middleton \& D. Edwards (Eds.), Collective remembering: memory in society (pp. 169189). Beverley Hills: Sage Publications.

Staw, B. M., \& Boettger, R. D. (1990). Task revision: a neglected form of work performance. Academy of Management Journal, 33(3), 534-559.

Thomas, R., \& Davies, A. (2005). Theorizing the micro-politics of resistance: new public management and managerial identities in the UK public services. Organization Studies, 26(5), 683-706.

Valsiner, J. (1994). Bi-directional cultural transmission and constructive Sociogenesis. In W. de Graaf \& R. Maier (Eds.), Sociogenesis Re-examined (pp. 101-134). New York: Springer.

Wrzesniewski, A., \& Dutton, J. E. (2001). Crafting a job: revisioning employees as active crafters of their work. The Academy of Management Review, 26(2), 179-201.

Wrzesniewski A., Dutton, J.E. \& Debebe, G. (2003). Caring in Constrained Contexts, Working Paper, New Haven: Yale.

Alison Fuller is Professor of Vocational Education and Work and Pro-Director (Research and Development) at UCL Institute of Education. Her research interests focus on workplace learning environments, workplace learning and workforce development, education - work transitions, vocational education, apprenticeship policy and as a model of learning. She has recently completed a study on adult apprentices for the Nuffield Foundation, with Lorna Unwin, Pauline Leonard and Gayna Davey, and is currently researching the relationship between work, learning and employee-driven innovation in the healthcare sector in an ESRC LLAKES funded project. Alison is a member of the All Party Skills Commission and a non-executive trustee of Semta (the employer-led body for skill formation in engineering and advanced manufacturing).

Lorna Unwin is Professor Emerita (Vocational Education) and Honorary Professor in the LLAKES Research Centre at the UCL Institute of Education, London. She is also Honorary Professorial Research Fellow, School of Environment, Education and Development, University of Manchester. Her research interests focus on organising workplaces as sites for learning, the role of education and training in urban (re)development, and the history of technical education, including apprenticeship, in the UK. Previously she was Deputy Director of the Centre for Learning and Life Chances in Knowledge Economies and Societies (LLAKES). She was Chair of the Inquiry into Group Training Associations from 2011 to 2012 and academic adviser to the Commission on Adult Vocational Teaching and Learning (CAVTL) from 2012 to 2013. 